\title{
Editorial
}

\section{Understanding the behaviour of financial services consumers: A research agenda}

Understanding consumers and their behaviour is at the heart of marketing. In recent times, there has been a preoccupation among financial institutions with customer retention and relationship marketing - essentially understanding the behaviour of consumers after the initial purchase has been made and focusing on how to maintain the relationship and manage it profitably. This is crucial to financial institutions, and recognises the ongoing nature of the relationship and longevity of many financial products. Yet, preoccupation with retention issues has meant that less attention has been focused on understanding the processes that consumers go through in making a purchase decision in the first place.

The need for research to focus both conceptually and empirically on consumer behaviour in the financial services context is clear. For example, the inherent characteristics of financial services (notably intangibility and fiduciary responsibility) compound many of the difficulties consumers experience generally with service selection. Moreover, many financial products represent significant, and often one-off, purchase decisions for consumers; the consequences of poor decision making can be severe. To complicate the matter further, the consumer is now faced with an increasing assortment of products from a variety of financial institutions (both domestic and foreign) and an uncertain marketplace.
In the academic literature there have been relatively few attempts to develop models that explain consumer decision processes specifically in the context of financial services. A considerable amount of theoretical and empirical work exists relating to how consumers make decisions, yet the majority of it has been developed for tangible goods rather than services, or even financial services.

The majority of the literature on general consumer buyer behaviour is centred around consumer behaviour models which were developed in the late 1960s. One of the frequently cited models is the Engel-Kollat-Blackwell model which breaks decision making down into five discrete but interlinked stages: problem recognition, information search, evaluation of alternatives, purchase decision and postpurchase evaluation. A common feature of such 'response-hierarchy' models, is that they are built around the 'information processing' model or the AIDA model (Awareness, Interest, Desire and Action). These models assume that buyers pass through cognitive, affective and behavioural stages when there is a high degree of involvement in a product category which is perceived to have a high degree of differentiation of products within it. Thus, the models imply that consumers first search for information about possible alternatives and their attributes, they then compare a number of 
selected alternatives and evaluate them on their attributes, and, once the purchase decision is made, the product is reevaluated to assess whether it was the correct decision.

The models have attracted criticism over the years, but in the absence of any new development they continue to be used. By breaking down the decision process to take account of pre-purchase, purchase and post-purchase activity, the relevance of the models to financial services consumer behaviour can be assessed. The following sections provide an overview of financial services consumer behaviour issues in each of the three stages of decision making and highlight areas for further research.

\section{PRE-PURCHASE INFORMATION SEARCH}

Prior to making a purchase decision, consumers can gather information from a variety of sources. For example, they can engage in pre-purchase trial of the product, they can observe the product's characteristics and qualities, and they can rely on the experience of others who have already used the product. Thus, prepurchase information can be broadly categorised as being from an internal source (memory, knowledge or experience) or an external source.

Where internal information is not available or is insufficient, the consumer may be motivated to search externally for information. External sources of information can be either personal in nature (such as a recommendation from friends or relatives and positive, or negative, word-of-mouth) or non-personal (such as marketer-generated advertising, or non-marketer generated publicity). The extent of external search in which the consumer engages is argued to be dependent on a number of factors. These include previous experience of the product category, the complexity of the product and the degree of uncertainty felt by the consumer. Since product complexity and buyer uncertainty are almost certain to exist in the case of many financial services purchases, the need for external sources of information would seem to be important in reducing the risk associated with the purchase.

While both personal and non-personal sources of information can be used quite successfully in the marketing of a broad range of physical goods, there can, however, be difficulties in communicating experience qualities of financial services through conventional forms of promotion. As a consequence of this, it has been argued that internal sources of information and external sources of a personal nature are the most appropriate in situations where experience qualities dominate and when objective standards by which to evaluate the product decrease. The importance of word-of-mouth communication in the context of financial services has been noted.

In terms of pre-purchase activity, research is needed to assess:

- the extent of pre-purchase information search for a variety of financial products (including simple and complex products)

- the type and nature of information sought

- the value consumers place on different types of financial services information

- the role that information plays in shaping consumers' preferences, attitudes and purchase behaviour.

\section{EVALUATION OF ALTERNATIVES}

Traditional consumer behaviour models suggest that the process of information search leads to the comparison between alternative products and suppliers. From the information gathered it is argued that 
the consumer develops an 'evoked set', a small number of products and/or suppliers from which the final choice will be made. Thus, the decision is assumed to be a rational and informed choice.

Difficulties of obtaining (and also utilising) pre-purchase information about financial services are likely to result in a smaller evoked set than for physical goods: the evoked set may consist of only one financial institution, particularly if the information gathered was from a personal source.

In situations where products are compared, evaluations of product quality occur on the basis of product attributes. With physical goods there are normally many cues that can be used to judge the quality of the product. For financial services the cues are generally more limited due to intangibility and longevity. Consequently, peripheral cues are often used to make an assumption about the level of service quality. Generally consumers are looking for cues which will give an indication of the likelihood that the financial institution will honour its promises. The physical facilities housing the service can be particularly useful in providing an indication of the professionalism of the organisation, as too can the size, reputation and history of the company. The customer contact staff are also important in enabling the consumer to establish a level of trust in the organisation.

As a result of lack of pre-purchase information for many financial services, it is argued that the decision processes consumers go through generally do not fit with the traditional 'learning-response' and 'low involvement' models. Where these models generally assert that consumers seek information and evaluate products prior to purchase, financial services buyer behaviour perhaps fits more closely with the dissonance response (reducing) model where most evaluation occurs after purchase.

Thus, research is needed to assess:
- how consumers evaluate financial services, what key attributes are sought, used and valued in evaluations, and whether these differ by product type

- the extent to which decisions are rational and based on informed choice

- the extent to which information processing and evaluation fits the learning-response pattern.

\section{POST-PURCHASE EVALUATION}

The post-purchase evaluation stage is important to consumers as a means of building experience and knowledge. Consumers evaluate products on the basis of whether they have fulfilled predetermined needs or met expectations. This in itself may pose some problems with financial services since there may not have been a perceived need to begin with but simply a legal obligation to buy, as in the case of car insurance for example. Moreover, the 'need' for the financial product may have been generated from a financial adviser. Thus, the consumer may find it difficult to evaluate the product in the absence of any of their own predetermined needs or specifications. Furthermore, as many financial products are high in credence qualities, it might be argued that for many consumers it is simply impossible fully to evaluate the quality of the product outcome.

For many financial services the process of evaluating is more complex because the consumer is evaluating the product before it has actually been consumed. For example, when consumers begin an investment plan, they cannot really evaluate the quality of the outcome until its maturity. They may, however, be forced to make some evaluation of the decision made.

The problem also arises when consumers do not have the knowledge or the experience to evaluate what they have received. Maybe their expectations of 
what they wanted from the financial institution are not clear. It may be difficult for the consumer to evaluate whether the investment product has performed optimally, so they make their evaluation on other attributes which are discernible to them. It is argued that the delivery mechanism of the service (including the physical process of delivery, any systems involved and personnel) becomes one of the key attributes against which the service is evaluated. Hence, customers are more likely to focus on the 'functional quality' of the product (for example: the willingness of counter and telephone staff, the knowledge and courtesy of staff, the empathy of staff towards the customer's needs and any signs, symbols and artefacts of service delivery), rather than the 'technical quality' of the product.

Research is needed to assess:

- the extent to which consumers reevaluate products after purchase

- the form that re-evaluation takes (functional or technical evaluation)

- the impact of re-evaluation on learning and knowledge building

- the impact of post-purchase evaluation on future purchasing decisions.
Moreover, there is a need for longitudinal research that attempts to take account of the process of decision making, rather than snapshot views that are often derived from single sample surveys. Longitudinal studies could include:

- Panel data

- Diaries

- Accompanied shopping

- Participant observation

- Repeated surveys, qualitative etc.

It is hoped that these ideas for research may inspire further research into financial services consumer behaviour and decisionmaking processes. The areas suggested represent just some of the topics relevant to a forthcoming special issue on 'Consumers and Consumption: The Opportunities and Challenges of Meeting Consumers' Aspirations'. The Call for Papers for this special issue is advertised at the back of this issue, and there is still plenty of time to put some of these ideas in motion!

Tina Harrison Managing Editor June 2003 